\title{
Who to ask for help? Do dogs form an opinion on humans based on skilfulness?
}

Patrizia Piotti*, Rebecca Marie Spooner, Hoi-Lam Jim, Juliane Kaminski

Department of Psychology, University of Portsmouth, King Henry Building, King Henry 1st Street, Portsmouth, P01 2DY, UK

*Patrizia.piotti@yahoo.it

\section{Highlights}

- Two studies used an unsolvable task to investigate reputation forming in dogs.

- First: dogs did not differentiate between a skilful and an unskilful experimenter.

- Second: dogs witnessed a skilled or unhelpful and friendly or ignoring experimenter.

- Here dogs looked longer at the experimenter if skilled, with a trend to significance.

- The results cannot confirm that dogs can use skilfulness to evaluate humans.

\section{Abstract}

Reputation is considered a fundamental mechanism for cooperation. Dogs can use their direct experience to form reputation judgments about humans that are either nice or not towards others, however it is unknown if dogs can take skilfulness into account when requesting human help. Here, we investigated reputation formation based on human skilfulness. In study 1, 32 adult pet dogs witnessed four blocks of two demonstration types: a skilful experimenter succeeded in solving a puzzle and obtaining food for the dog, while an unskilful experimenter failed. Each block was followed by an unsolvable task trial, where the dogs were presented a container baited with food that was inaccessible to the dog. During the task, the experimenters stood on either side of the container. Referential looks towards each experimenter were recorded. Dogs did not choose the skilful experimenter above chance and did not prefer the skilful experimenter over the unskilful one. In order to simplify the task and avoid carryover effects, in a second study dogs only witnessed one type of demonstration and were then tested in a single unsolvable task trial. To further simplify the demonstrations, the experimenter either skilfully helped the dog (skilful demonstration), or did not help the dog at all (no-help demonstration). Forty-eight dogs were allocated to one of four demonstration groups: demonstrations could be either skilful or with no-help ("skilfulness" variable) and nice or ignoring ("quality of interaction" variable). Dogs' looking back behaviour did not differ in any of the conditions. However, when pooling the "quality of interaction" groups to compare the two "skilfulness" groups, a trend towards significance was observed between the duration of looking in the skilful group and the non-helpful group (Wilcoxon signed rank test: $M d n_{\text {skilful }}=9.20$, interquartile range 3.98-20.65; $M d n_{\text {no-help }}=4.90$ interquartile range 1.35-8.58, $T=1.93, p=0.05, r=-0.39$ ). The results should be considered cautiously and 
cannot confirm that dogs could take skilfulness into account when looking referentially at humans for help, or use the information to evaluate them in this specific context.

\section{Keywords}

Reputation; Unsolvable task; Referential; Looking back; Dog; Help request

\section{Introduction}

Reputation is the ability to gain knowledge about an individual's common behaviour through the individual's past behaviour (Melis and Semmann 2010) to form a set of collective beliefs, perceptions, or evaluative judgments about someone (Emler, 1990 ; Sperber and Baumard, 2012). Reputation is considered a crucial element of cooperative interactions as it allows, for example, recruitment of the best collaborative partner (Wedekind and Milinski, 2000 ; Wu et al., 2016) and avoidance of exploitation (Axelrod and Hamilton 1981). For example, humans monitor the roles of other individuals and choose future collaborators on the basis of individuals' past behaviour (Trivers, 1971 ; Fehr and Fischbacher, 2004). Starting from a very young age, human children identify and recruit the most effective collaborators when they need help in solving a problem (Tomasello et al., 2005 ; Warneken et al., 2006), and they can form an opinion about others based on both their direct and indirect experience (Herrmann et al., 2013). There is some evidence that other primates, such as chimpanzees and orang-utans (Melis et al., 2006; Subiaul et al., 2008 ; Herrmann et al., 2013), can identify and recruit a collaborative partner based on their direct experience and, to some extent, after observing third party interactions (Herrmann et al., 2013). Recently, comparative research showed that species evolutionarily more distant from humans, such as fish (Vail et al., 2014), ravens (Asakawa-Haas et al., 2016), and dogs (Horn et al., 2012) also form preferences in choosing their collaborative partners. However, the cognitive mechanisms underlying this skill are still unclear (Asakawa-Haas et al., 2016).

Dogs are a species of particular interest for the comparative study of social skills, due to their unique ability when it comes to communicate with humans (Cooper et al., 2003; Miklósi et al., 2004). One hypothesis is that dogs' outstanding skills are the result of a unique domestication process (Hare et al., 2002 ; Miklósi et al., 2004), during which dogs adapted to life with humans and formed a specialization for communication with humans, especially in cooperative contexts (Bräuer et al., 2006 ; Reid, 2009). An alternative hypothesis, the "TwoStage Hypothesis", emphasizes the effect of ontogenesis (Wynne et al., 2008 ; Udell et al., 2010), suggesting that the capacity to interact with humans is acquired after having accepted humans as companions throughout the early ontogeny and being given the opportunity to learn from them during life (Udell et al., 2010 ; Udell and Wynne, 2010).

A wealthy body of research indicates that dogs can form an opinion about humans based on their direct experience, such as interacting with someone nice 
versus someone ignoring them (Nitzschner et al., 2012). Findings regarding dogs' ability to evaluate humans based on indirect experiences are more controversial (Marshall-Pescini et al., 2011; Freidin et al., 2013; Nitzschner et al., 2014 ; Chijiiwa et al., 2015). One area that is largely understudied is dogs' ability to take into account their opinion about humans in a cooperative context. There is evidence that dogs would use a specific behaviour, called looking back, to seek human help when they cannot solve a problem (Miklósi et al., 2003). Therefore, looking back represents an interesting behaviour that can be used to measure dogs' tendency to recruit human help. Horn et al. (2012) investigated whether dogs could discriminate two experimenters based on their skills (i.e. filling an empty food-toy, rather than unlocking the toy when it was blocked), and whether dogs would also use this looking back behaviour to request help from the most appropriate partner based on the problem at hand (i.e. an empty apparatus or a locked apparatus). While dogs looked back equally at either experimenter, the differing amount of time spent close to the experimenters showed that dogs could possibly discriminate the two (Horn et al., 2012). Petró et al. (2016) replicated the work by Horn et al. (2012) but substituted the human partners with inanimate interactive agents. In this study, dogs initially looked more at the most appropriate agent, based on the context (i.e. when a filler was required or when a helper was required), though the behaviour faded with trials. The authors concluded that the dogs most likely associated the action of either inanimate agent with the specific location where the food was hidden (Petró et al., 2016). Therefore, it remains unclear whether dogs can discriminate humans based on skilfulness and subsequently use this information to request help from the best collaborators.

In the current study, we adapted the original test that was designed to study canine help requests through the measure of the looking back behaviour, i.e. the unsolvable task paradigm ( Miklósi et al., 2003). In the unsolvable task, dogs are initially given access to some food that they can retrieve from below a container, in the presence of a human partner. After a few successful retrievals, the apparatus is altered so that the food becomes inaccessible, thus the task becomes unsolvable. Dogs have been found to respond by looking back at the human, which has been interpreted as a request for help ( Miklósi et al., 2003). Although it is not yet known how flexibly dogs can take into account their past experience with a human partner when requesting their help, there is evidence that the looking back behaviour during the unsolvable task is largely affected by past experience. For example, dogs trained for agility or water rescue gaze more at humans compared to search and rescue dogs or untrained dogs (MarshallPescini et al., 2009 ; D'Aniello et al., 2015) and pet dogs gaze more than kennelled dogs (D'Aniello and Scandurra 2016).

We designed two experiments to investigate the effect of direct experiences with humans on dogs' looking back behaviour. In Study 1, we examined whether dogs would prefer to look at a skilful partner over an unskilful one during the unsolvable task. However, it is possible that dogs can only take into account other social elements of their interactions with humans, such as being nice ( Nitzschner et al., 2012), rather than skilfulness. It may also be difficult for dogs to discriminate between two partners in the unsolvable task. Therefore, in Study 2, 
there was only one experimenter, who acted either skilful or unskilful, and either interacted with the dog in a friendly way or ignored the dog.

\section{Study 1}

The aim of this study was to investigate whether dogs can form an opinion about humans, based on their direct experience observing skilful and unskilful human partners during a problem-solving task, and subsequently recruit the best helper when they face an unsolvable task. Since dogs can form an opinion about humans based on their direct experience ( Nitzschner et al., 2012), and dogs' gazing behaviour toward humans is influenced by previous collaborative experiences (Marshall-Pescini et al., 2009; D' Aniello et al., 2015), we expected the dogs to gaze more at the skilful experimenter during the unsolvable task. The overall study design was similar to Nitzschner et al. (2012). Dogs had different demonstrations with two experimenters (Patrizia Piotti, PP, and Rebecca Marie Spooner, RMS). If dogs are able to use skilfulness to form an opinion about humans, then they should be able to transfer their opinion to a different task; therefore it was decided to use two different tasks for the demonstration and the test. This was necessary in order to ensure that the dogs did not choose an experimenter based on associative mechanisms, such as social or stimulus enhancement. One experimenter skilfully operated a problem-solving toy, while the other attempted but failed. Immediately afterwards, dogs were presented with the unsolvable task in the presence of the two demonstrators (test phase). Since the procedure adopted by Nitzschner et al. (2012) proved to be successful in allowing dogs to discriminate humans based on social cues, this study was also conducted using the same number of testing trials; therefore dogs experienced four blocks of demonstrations and four tests overall.

\subsection{Material and methods}

\subsubsection{Ethical statement}

All applicable international, national, and/or institutional guidelines for the care and use of animals were followed. All procedures performed involving animals were in accordance with the ethical standards of the institution at which the studies were conducted (the University of Portsmouth, U.K.). The studies were carried out in strict accordance with the recommendations in the International Society for Applied Ethology guidelines for the use of animals in research and were approved by the University of Portsmouth Animal Ethics Committee (Animal Welfare and Ethical Review Body, AWERB, approval n. 515a). Informed consent was obtained from all owners for their dog to participate in the study.

\subsubsection{Apparatus and testing areas}

Previous studies on reputation forming in dogs indicate that dogs may associate a specific location with food, rather than choosing a human partner based on his/her characteristics (Nitzschner et al., 2014 ; Petró et al., 2016). Therefore, in the current study, two different apparatuses were used for the demonstration phase and test phase, referred to as the problem-solving apparatus and the 
unsolvable task apparatus respectively. These phases took place in two adjacent rooms of the Dog Cognition Centre Portsmouth (Fig. 1). Video recordings in the Demonstration Room were taken using a Sony Digital SMX-C10 camera positioned in a corner of the room; in the Test Room they were taken with a GoPro Hero 3+ camera positioned above the apparatus.

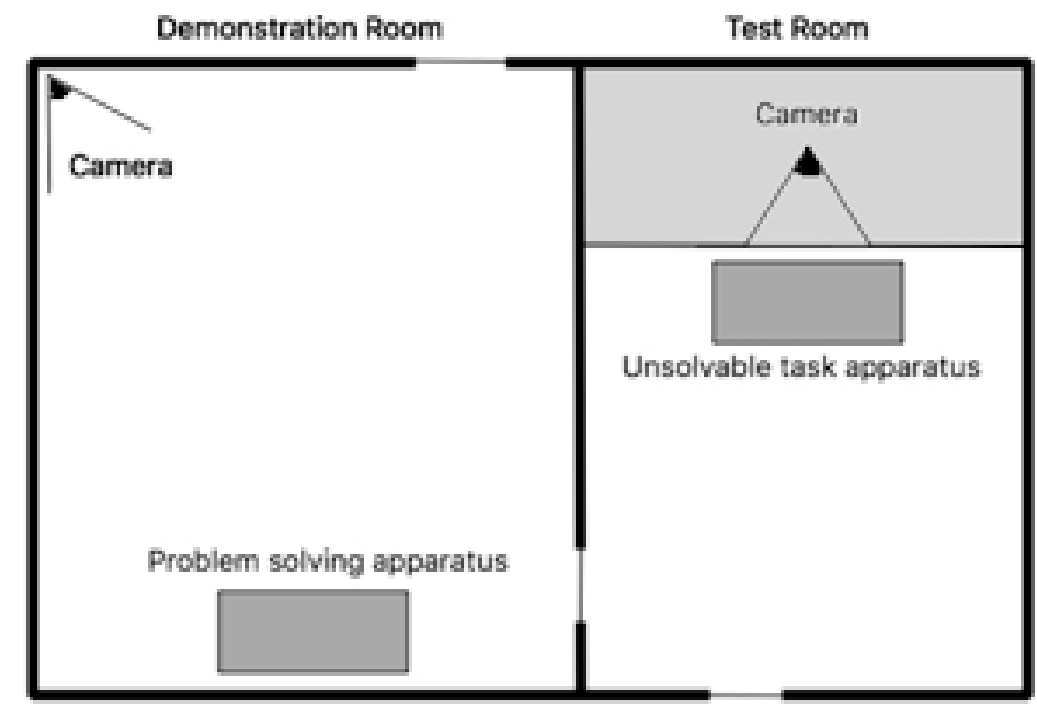

Fig. 1.

Testing rooms.

The two rooms were connected by an internal door. The dark grey squares in each room represent the apparatuses. In the Test Room, the access to the light grey area was blocked through a fence and was inaccessible to the dog, in order to facilitate the video recording.

The problem-solving apparatus (Fig. 2) consisted of a wooden frame holding 3 plastic bottles with no lid, each containing one piece of dry dog food. The bottles needed to be turned upside down and a piece of cardboard, which acted as a divider obstructing the bottles' neck, had to be pulled out to release the treats. 


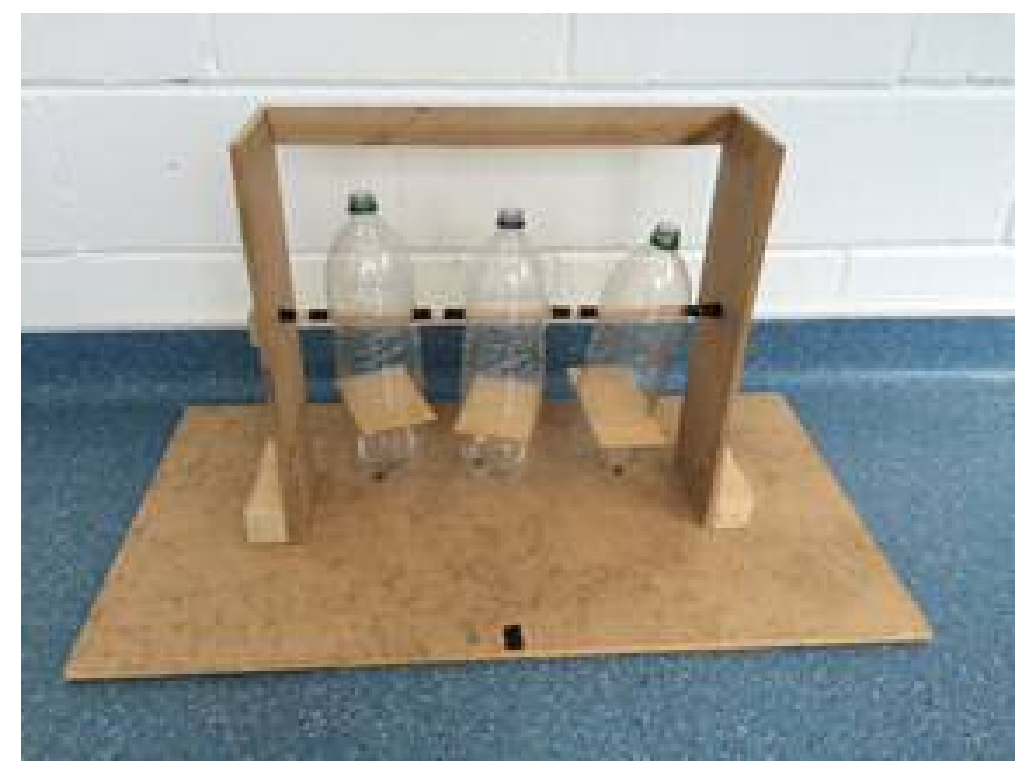

Fig. 2.

Problem solving apparatus.

The apparatus consisted on a wood frame with three bottles on a rod that could rotate on their longitudinal axis. A piece of dry food is visible at the bottom of each bottle; a small wood partition was inserted transversally in the bottle. Therefore, in order to retrieve the food it was necessary to flip the bottle upside down and then pull the wood flap away.

The unsolvable task apparatus was a variation of the apparatus used in Miklósi et al. (2003). A piece of sausage was placed in a transparent plastic container that was attached to a wooden board. In the unsolvable task (Fig. 3), the container was covered with a metal basket attached to the board, so that the dogs could not remove it, and thus could not reach the food.

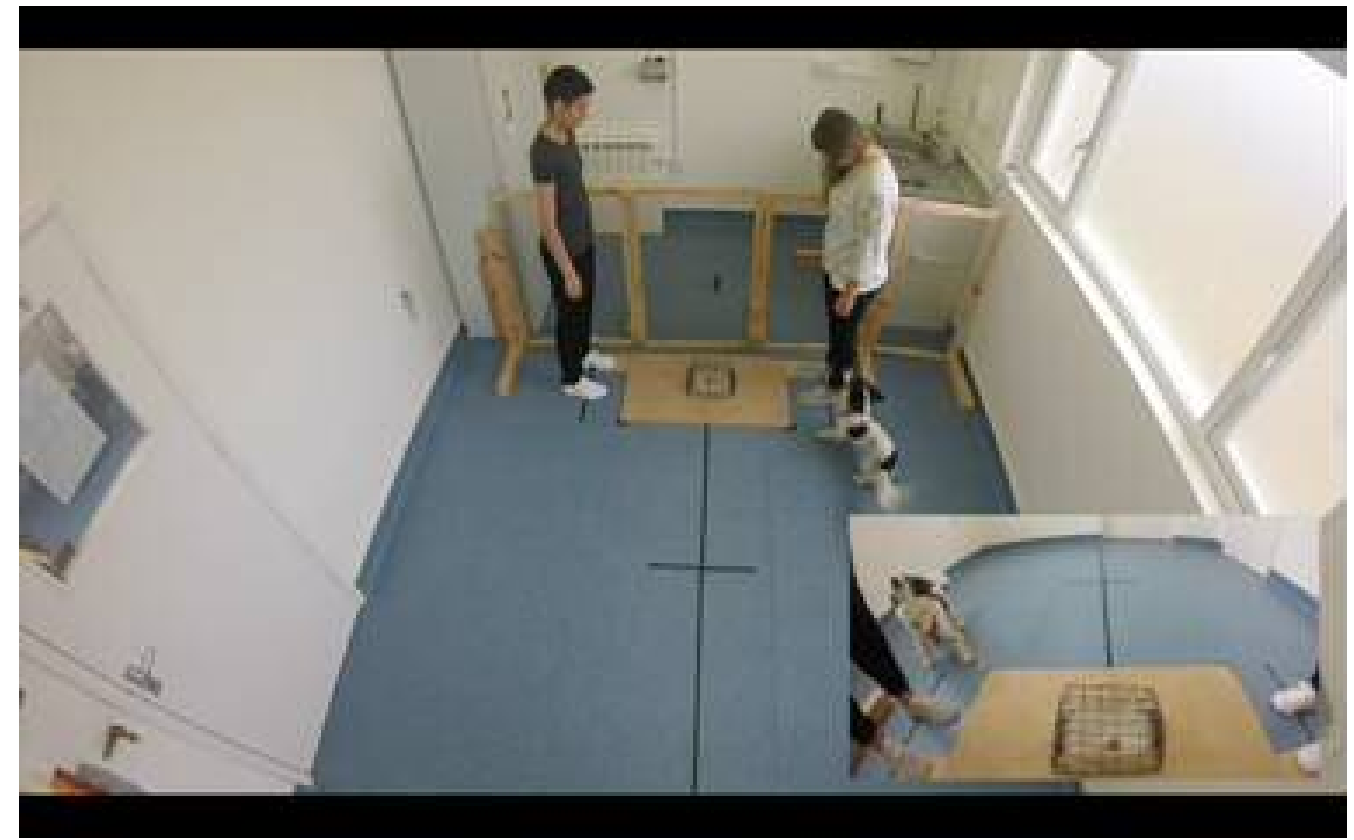

Fig. 3. 


\section{Example of looking back behaviour during the unsolvable task.}

A looking back behaviour was recorded when the dog turned and lifted their head and/or eyes toward the head of one of the two experimenters.

\subsubsection{Participants}

A sample of 32 pet dogs was used, including 8 females and 24 males $\left(M_{\text {age }}=4.43\right.$ years, $\mathrm{SD}_{\text {age }}=2.61, \mathrm{Min}_{\text {age }}=1.00$ year, $\mathrm{Max}_{\mathrm{age}}=10.00$ years $)$. Of these, 18 dogs (56\%) were pure breeds (Online Resource 1). The inclusion criteria were for the dogs to be between 1 and 11 years old, to be able to visit the Dog Cognition Centre Portsmouth with their owner and be comfortable when separated from their owner. Dogs that had previous experience with the experimenters were excluded from the experiment. Some of the dogs had participated in other studies of the Dog Cognition Centre, however none of them were similar to the current study. Participants were recruited through the Dog Research Study Register of the University of Portsmouth and personal contacts.

\subsubsection{Procedure}

The overall procedure resembled that of Nitzschner et al. (2012). The dogs witnessed a series of demonstrations performed by two experimenters; each dog observed two types of demonstrations based on the experimenter's role, i.e. skilful or unskilful. Dogs were then tested with a variation of the unsolvable task, similar to that used by D'Aniello et al. (2015), in order to allow two experimenters to be present in the room. The test phase of the unsolvable task is typically preceded by a few solvable trials, for the dogs to understand that they can access the food ( Miklósi et al., 2003). In this study we did not want to distract the dogs after the demonstrations, therefore they were presented with the solvable trials as soon as they arrived. Afterwards, the dogs were exposed to the demonstrations and the unsolvable task trials. The 3 phases (solvable trials, demonstrations and unsolvable task) followed the procedure below:

\subsubsection{Solvable trials}

after the dog's owner agreed for their dog to participate in the study, a handler walked the dog across the Demonstration Room to the Test Room (Fig. 1), where there was a plastic container fixed on a wooden board, containing some dog treats. The dog was allowed to eat the food and the handler refilled the container; this was repeated a further two times. The handler then took the dog outside so that the experimenters could enter the rooms and prepare for the demonstrations. The handler and the dog waited near the demonstration room, in a position from which the handler could see what was happening inside the room through a window, but the dog could not.

\subsubsection{Skilful and unskilful demonstrations}

For each demonstration only one experimenter was in the Demonstration Room, while the other waited in the Test Room. At the beginning of each demonstration 
block, the first experimenter placed the problem-solving apparatus in position in the Demonstration Room and refilled it as necessary, then she signalled for the handler to enter the room. The handler walked the dog up to the apparatus and held it by its lead so that it was approximately a head's distance from the apparatus, i.e. the dog was close to the demonstration but not close enough to disrupt it. Both experimenters talked to the dog during the demonstration to ensure it watched. During the skilful demonstrations, the skilful experimenter "helped" the dog by performing the correct sequence of movements necessary to solve the problem and retrieve the food, which the dog could then eat. On the contrary, in the unskilful demonstrations, the unskilful experimenter performed ineffective movements that could not solve the problem, i.e. the food was not retrieved from the bottles. It was necessary to ensure that dogs received the same amount of food during both demonstrations, to avoid any food related bias. We could either give food in both conditions or in none of them. It was decided to give food to the dogs in both conditions to ensure that dogs were motivated to look at the demonstration and that the task was relevant to the dogs. Therefore, after interacting with each bottle, the unskilful experimenter inconspicuously dropped a piece of food from her pocket for the dog to find and eat a total of 3 pieces. To ensure that the dogs could not notice that the food came from the experimenter, both experimenters kept their hand in a special pocket, which had a funnel and a hole in it to allow them to drop the food in the same area where it fell during the skilful demonstration. This way the dogs received the same amount of food in both types of demonstrations. In order to control for odour cues, both experimenters had three pieces of food in their pocket during the demonstration. At the end of each demonstration, the experimenter said: "All done!" if it was a skilful demonstration or "I don't get it!" if it was unskilful. On this cue, the handler walked the dog out of the room again, so that the two experimenters could exchange rooms unseen by the dog. The order of the demonstrations was counterbalanced so that half of the dogs started with the skilful demonstration and the other half with the unskilful one. Also, PP was the skilful demonstrator for half of the dogs and RMS for the other half.

Demonstrations were presented in a semi-randomised order, with the stipulation that the same demonstration was not repeated more than twice in a row.

\subsubsection{Unsolvable task trial}

After the demonstrations, both experimenters entered the Test Room and stood at the two sides of the apparatus. The handler led the dog into the room and placed a piece of sausage in the apparatus, let the dog off the leash and then left the room for one minute leaving the dog behind in the test room with the two experimenters. Since the dogs had previously experienced that food was accessible from the apparatus (solvable trials), they initially tried to reach the piece of sausage. Upon realising it was now inaccessible due to the metal basket, the dogs were expected to engage in other behaviours, including requests to the two experimenters (e.g. gaze alternations between the humans and the food). For the duration of the test, the experimenters stood still and kept their gaze on the food basket to ensure they did not influence the dog in any way ( Fig. 3). 
After each test the handler took the dog away for another demonstration block; after the fourth test the study was over.

In summary, the dogs underwent the following procedure: they experienced 3 solvable trials, followed by 4 demonstrations ( 2 skilful and 2 unskilful) and 1 unsolvable task trial. Three similar blocks followed, each of them consisted of 2 demonstrations ( 1 skilful and 1 unskilful) followed by 1 unsolvable task trial.

\subsubsection{Behaviour analysis}

Digital video footage was taken for all trials and the Solomon Coder software (beta 091110, copyright 2006-2008 by András Péter, developed at ELTE TTK Department of Ethology, Budapest, Hungary) was used to code dogs' behaviour during testing.

Dog behaviour was measured from the moment the handler released the dog from the lead, and concluded when $60 \mathrm{~s}$ had elapsed, which was just prior to the handler returning to the testing room. Because during the test it was not always possible to centre the dog between the two experimenters before releasing it, it was not possible to code data regarding dogs' proximity to each experimenter. Dogs' looking behaviour was recorded based on the orientation of the head and/or eyes of the dog. As suggested by Smith and Litchfield (2013), the term gaze is avoided because it was not always possible to determine the direction of the eyes, but only the orientation of the head/nose of the dog. The term looking is used instead.

Looks toward two specific targets were recorded: 1) looking at food was recorded each time the head of the dog was directed towards the basket containing the food; 2) looking back was recorded when the dog turned and lifted their head and/or eyes toward the head of one of the two experimenters. Looks towards the skilful and the unskilful experimenter were recorded separately. As we were interested in dogs' help requests, we only recorded looks that were referential, according to the definition by Smith and Litchfield (2013), which we adapted to allow for the presence of two experimenters: i.e. looks included a sequence between food and one or both experimenters (and vice versa). Only unbroken looks lasting at least $0.2 \mathrm{~s}$ were recorded and a gap of no longer than $2 \mathrm{~s}$ from the end of each look and the beginning of the following one was allowed, as suggested by Gaunet and Deputte (2011) and Marshall-Pescini et al. (2009).

For each look, the latency to look (i.e. time between the beginning of the test and the dog orienting their head/eyes toward an experimenter or the food) was recorded, as were the frequency and duration of the looks. The first experimenter that dogs looked at was also recorded.

One experimenter (PP) coded the video material and a random selection of the video material (20\%) was coded by a second coder, naïve to the role of each experimenter. The correlation between the two coders was calculated using Spearman $r$ and inter-coder reliability was assessed according to the limits given 
by Landis and Koch (1977). Inter-observer reliability was excellent for the durations of looks to the experimenters (RMS: $r_{s}=0.80, N=24, p=0.01$; PP: $\left.r_{s}=0.84, N=24, p<0.01\right)$ and frequency of looks towards RMS $\left(r_{s}=0.84, N=24\right.$, $p<0.01$ ); it was substantial for the frequency of looks toward PP $\left(r_{s}=0.76, N=24, p<0.01\right)$ and latency to look towards PP $\left(r_{s}=0.74, N=24\right.$, $p<0.01)$; it was moderate for the latency to look toward RMS $\left(r_{s}=0.51, N=24\right.$, $p=0.01)$.

\subsubsection{Statistical analysis}

Data were analysed using IBM SPSS Statistics version 22. The KolmogorovSmirnov test for normality revealed that the data were not normally distributed, thus non-parametric tests (two-tailed) were used. Measures were averaged across trials for each dog before performing the statistical analysis, so for every variable measured, the mean value across the four test trials was used.

\subsection{Results}

Overall, $97 \%$ of the dogs looked at an experimenter in at least one of the trials. Trials where dogs never looked at the experimenter (14\%) were excluded from further analysis.

The initial analysis was on the experimenter that dogs looked at first. For each dog, the percentage of trials where they looked at the skilful experimenter was calculated after excluding the trials in which the dogs did not look at either experimenter (one dog was excluded from the analysis because did not look at the experimenters). A one-sample Wilcoxon signed rank test indicated that dogs choose the skilful experimenter below chance level, i.e. $50 \%(\mathrm{Mdn}=0.50$, interquartile range $=0.25-66), N=31, z=-4.87, p<0.001$, with a large effect size $(r=-0.87)$.

The following analysis regarded the duration, frequency and latency to look at each experimenter. Because it was possible that the dogs' help-seeking behaviour had declined across trials, the first trial has initially been analysed alone (dogs that did not look have been excluded from the analysis). Wilcoxon signed rank test showed that the looks towards the skilful and the unskilful experimenter did not differ for frequency, latency or duration (Table 1).

Table 1.

Median duration of looking back at the skilful experimenter versus the unskilful experimenter during the first trial, results of related-measures Wilcoxon signed rank test $(N=27)$.

\begin{tabular}{|c|c|c|c|c|c|c|c|}
\hline & \multicolumn{2}{|l|}{ Skilful } & \multicolumn{3}{|c|}{ Unskilful } & \multirow[b]{2}{*}{$p$} & \multirow[b]{2}{*}{$r$} \\
\hline & $\overline{M d n}$ & $I Q R$ & $M d n$ & $I Q R$ & $Z$ & & \\
\hline Frequencies & 1.00 & $0.00-2.00$ & 1.00 & $0.00-2.00$ & -.17 & 0.86 & -0.02 \\
\hline Latencies (seconds) & 35.40 & $12.8-60.00$ & 33.00 & $14.80-60.00$ & .14 & 0.88 & 0.02 \\
\hline Durations (seconds) & 1.20 & $0.00-2.50$ & 1.40 & $0.00-5.00$ & .44 & 0.66 & 0.06 \\
\hline
\end{tabular}


In order to avoid incurring pseudo-replication (Hurlbert, 1984), all subsequent analyses were performed on the data aggregated by calculating the median value across trials. The duration, frequency and latency of looking back indicated that dogs did not prefer the skilful experimenter over the unskilful one (Table 2).

\section{Table 2.}

Median measure across all trials of looking back at the skilful experimenter versus the unskilful experimenter, results of related-measures Wilcoxon signed rank test $(N=31)$.

\begin{tabular}{|c|c|c|c|c|c|c|c|}
\hline & \multicolumn{2}{|l|}{ Skilful } & \multicolumn{3}{|c|}{ Unskilful } & \multirow[b]{2}{*}{$p$} & \multirow[b]{2}{*}{$r$} \\
\hline & $\overline{M d n}$ & $I Q R$ & $M d n$ & $I Q R$ & $z$ & & \\
\hline Frequencies & 1.00 & $0.50-1.50$ & 1.00 & $0.50-1.50$ & -2.20 & 0.08 & -0.28 \\
\hline Latencies (seconds) & 37.33 & $19.11-53.98$ & 36.60 & $22.09-52.98$ & 0.01 & 0.99 & 0.01 \\
\hline Durations (seconds) & .60 & $.20-1.21$ & .57 & $0.38-1.34$ & -1.08 & 0.42 & -0.13 \\
\hline
\end{tabular}

Medians (Mdn) and interquartile ranges (IQR) have been reported; p-values have been corrected for multiple

comparisons using Benjamini and Hochberg (1995) method. Effect sizes $(r)$ were calculated dividing the test statistics by the square root of the number of observations (Pallant, 2007).

\subsection{Discussion}

This study investigated whether dogs would discriminate between two humans solely on the basis of the level of skilfulness they demonstrated in the previous problem-solving situation. Our test paradigm was the unsolvable task. In this context, dogs typically look at humans to request their help to retrieve some food. If dogs have this ability, they would be expected to preferably look at the most skilful partner. However, the results of this study did not indicate that the dogs formed a preference for either of the two experimenters, skilful or unskilful.

One explanation could be that dogs might not be able to form an opinion based on skilfulness, which could be a prerogative of humans and close relatives such as primates (Melis et al., 2006). Dogs are able to adjust their behaviour based on the skills of a human partner (Horn et al., 2012), however more parsimonious mechanisms, such as simple associations, may possibly explain this behaviour (Petró et al., 2017). One possibility is that dogs form an opinion about humans but only in certain contexts. For example, it is possible that dogs might form an opinion about humans based on how pleasant the interaction with them is, rather than skilfulness. Dogs have been found to prefer spending time near a human partner that interacted in a friendly way rather than one who ignored them (Nitzschner et al., 2012). In a recent study (Heberlein et al., 2016), it was also observed that dogs could discriminate between a cooperative human partner, who gave them food, and a competitive partner, who had some food but ate it. The dogs looked more at the cooperative partner than the competitive one; dogs were also more likely to indicate the location of some hidden food when the cooperative partner was in the room (Heberlein et al., 2016). This last study suggests that dogs adjust their communicative behaviour to their experience with humans. In a recent review of the literature, Abdai and Miklósi (2016) suggest that both concepts, being skilful and being "nice", are important in collaborative contexts and it may be difficult to completely separate them. It is 
possible that it was difficult for the dogs in the current study to prefer one experimenter over the other, as both acted equally nicely towards the dogs.

It may also be difficult for dogs to choose between the two human partners during the unsolvable task. D'Aniello et al. (2015) found that dogs were able to discriminate between two people during this test; however, in that study dogs were required to choose between the owner and a stranger. In the case of the current study, dogs were required to discriminate two strangers based on elaborate sequences of actions. It is possible that the dogs in our sample might not have fully understood the demonstration. Although this was designed as a direct experience for dogs, they did not have a chance to use the apparatus and potentially gain an understanding of how to use it. Previous findings suggest that dogs may have a limited understanding of how a physical problem can be solved by a human partner (Horn et al., 2012). For this reason, the dogs in the current study might have failed to fully recognise the experimenters' ability to solve a problem.

Finally, it should be taken into consideration that in this kind of studies, the subjects may also be affected by the behaviour of the experimenters during test trials (Abdai and Miklósi, 2016Abdai and Miklósi 2016). It is possible that the dogs in this study were influenced by the experimenters' behaviour during the unsolvable task trials, which was to ignore the dogs' help requests. When an anticipated reward is unexpectedly reduced, dogs often either show a successive negative contrast, i.e. a reduction in their responses ( Bentosela et al., 2009), or a paradox increase in their behavioural response (Reimer et al., 2016). The lack of reaction on the side of the experimenter is required in a paradigm such as the unsolvable task, therefore the effect of affective contrast should be taken into account in the analysis and interpretation of results. One way to overcome this issue is to design a test including only one test trial.

Therefore, it was necessary to design a second study where only one experimenter was present in the unsolvable task and dogs had a chance to directly experience the apparatus used in the demonstration. Moreover, the study assessed whether other elements that possibly are more relevant to dogs, such as the quality of the interaction, would influence dogs' looking back behaviour in the unsolvable task.

\section{Study 2}

The aim of this study was to investigate whether dogs form an opinion about humans based on their direct experience with a human partner. Conditions were administered in a two-by-two design, so that dogs had a direct experience with a human partner who was either nice or ignored the dog, and either skilful or not willing to help during a problem-solving task. The test was between subjects and examined whether dogs' in the four groups (Nice-Skilful, Nice-No-help, IgnoringSkilful, and Ignoring-No-help) varied in their tendency to request help from the experimenter when they faced an unsolvable problem. In order to avoid carryover effects, in this study each dog was exposed to only one demonstration and one unsolvable trial. 
Dogs can form a positive or negative opinion about humans based on their direct experience (Nitzschner et al., 2012) and dogs' gazing behaviour toward humans is influenced by previous collaborative experiences (Marshall-Pescini et al., 2009 ; D'Aniello et al., 2015). Therefore, it was expected that dogs would be more likely to look back at a nice and/or skilled experimenter.

\subsection{Materials and methods}

\subsubsection{Ethical statement}

All applicable international, national, and/or institutional guidelines for the care and use of animals were followed. All procedures performed involving animals were in accordance with the ethical standards of the institution at which the studies were conducted (the University of Portsmouth, U.K.). The studies were carried out in strict accordance with the recommendations in the International Society for Applied Ethology guidelines for the use of animals in research and were approved by the University of Portsmouth Animal Ethics Committee (Animal Welfare and Ethical Review Body, AWERB, approval n. 515a). Informed consent was obtained from all owners for their dog to participate in the study.

\subsubsection{Apparatuses and testing areas}

Testing took place in the same rooms of the Dog Cognition Centre of the University of Portsmouth (U.K.) as in Study 1, arranged in a similar way (Fig. 4). Two GoPro 3+ cameras were placed near the ceiling of both rooms, in order to provide an overview of the room. A third GoPro 3+ camera was placed on a chest harness worn by the experimenter in order to record looks toward her.

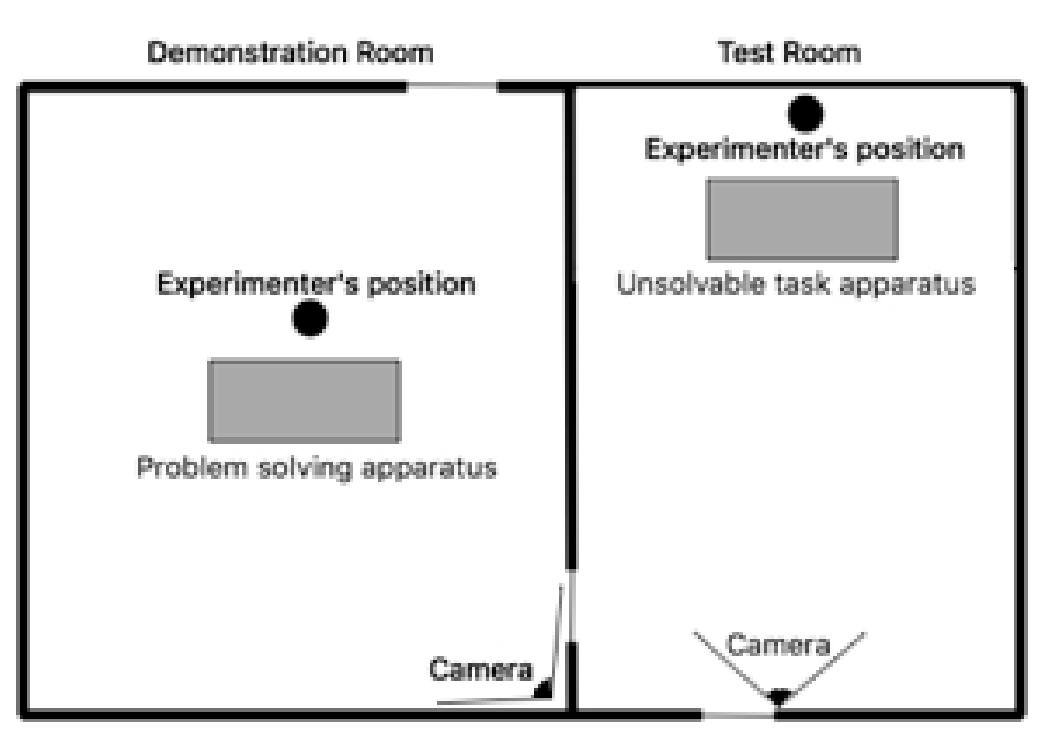

Fig. 4.

Testing rooms. 
The same rooms as in Study 1 were used. The dark grey squares in each room represent the apparatuses. The black circle near the square represents the position of the experimenter during the demonstration and during the test respectively.

The apparatus for the demonstration was a Nina Ottoson ${ }^{\circledR}$ Dog Fighter dog puzzle-toy (Fig. 5). The apparatus had a number of hollow slides that could be filled with food and wood blocks. The blocks had to be removed in a specific order and using certain movements in order to retrieve the food. Only 4 slides were used. The apparatus for the unsolvable task was the same as in Study 1.

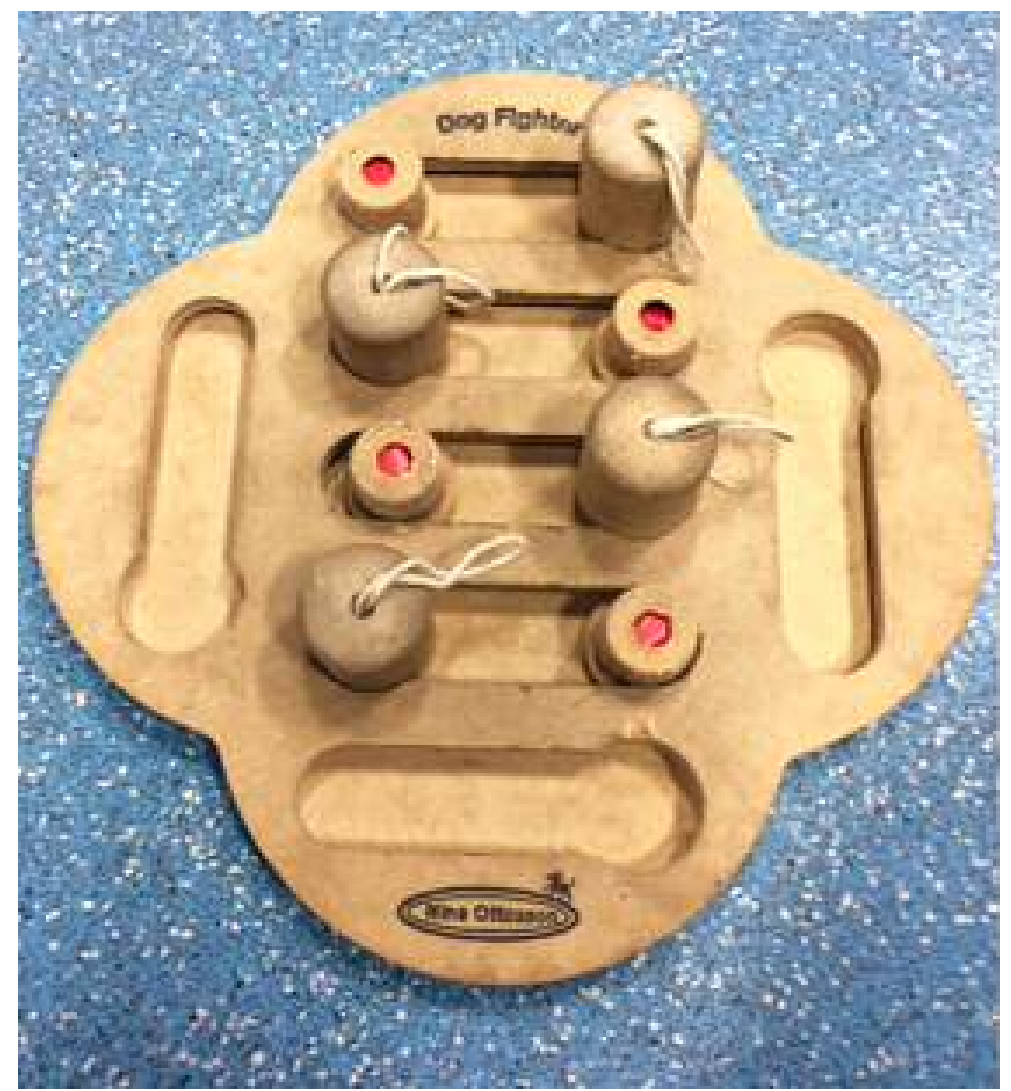

\section{Fig. 5.}

\section{Problem solving apparatus.}

The Dog Fighter puzzle-toy had 6 hollow slides with a large opening. Only 4 of the central slides were used. A small piece of hot-dog was placed under the small hollow block, which was placed at the opening and then slid across to the other end. A larger block was placed at the opening, which prevented the small block from being removed. In order to retrieve the food, it was necessary to pull out the large block first, then slide the small block across and remove it from the opening by pulling the attached string.

\subsubsection{Participants}

A sample of 48 pet dogs was used, of which 21 dogs were male (56\%) and 27 female $\left(M_{\text {age }}=4.17\right.$ years, $S D_{\text {age }}=2.71, \operatorname{Min}_{\text {age }}=1.00$ year, Max $_{\text {age }}=11.00$ years $)$. Overall, 31 dogs (65\%) were pure breeds. A breakdown of the dogs' information 
by condition is presented in the Online Resource 1 . The inclusion and exclusion criteria and recruitment method were the same as for Study 1; none of the dog had participated in Study 1. Another two dogs were tested but data were removed before further analysis due to procedural mistakes (1 dog) or because the dog had used the puzzle-toy before (1 dog).

\subsubsection{Procedure}

The study was comprised of: a habituation phase, in which dogs were given some time to get used to the testing area; a warm-up, in which dogs were given time to familiarise with and try to use the puzzle-toy that was later used in the demonstration, and the baseline level of looking back at a stranger (experimenter) was measured; a demonstration, in which the experimenter attempted to operate the puzzle-toy, acting either skilful or unskilful and nicely or ignoring the dog, according to the condition; and a test phase, in which the dog was tested with the unsolvable task.

\subsubsection{Habituation phase}

The handler (PP) played with the dog for a few minutes, letting it explore both the Demonstration and the Test Rooms, while offering some of the food used in the test (pieces of hot-dog). Both apparatuses were out of view at this stage and the experimenter was waiting outside. Once the dog was relaxed and interested in the food, the handler called the dog into the Demonstration room, closed the door between the two rooms and presented the problem-solving toy to the dog. At the same time, the experimenter entered the Test Room, unseen by the dog.

\subsubsection{Warm-up}

In this phase the dog was given time to try and familiarise with the puzzle-toy that was used in the demonstration. The handler put the dog on an $80 \mathrm{~cm}$ long lead and secured it to a wall hook. The handler placed the puzzle-toy on the floor, approximately 1 metre away and out of the dog's reach. Then, making sure the dog was watching, she filled the toy with the treats. She then unleashed the dog and walked it to the toy encouraging it to play. The dog was given $40 \mathrm{~s}$ to try and obtaining the food and solve the puzzle, while the handler stood nearby pretending to be busy whilst ignoring the dog. The amount of time had been previously piloted with dogs not used in this test. The aim was for the dogs to experience that the toy posed a problem difficult to solve; however, it was necessary to ensure that the dogs did not have enough time to solve the problem by themselves, so that they needed the help of a human partner and the following demonstration was relevant to them. After the time elapsed, the warmup was over.

\subsubsection{Demonstrations}

After the warm up, the handler attached again the dog to the lead that was fixed to the wall. The handler then opened the door between the two rooms and invited the experimenter (H-LJ) inside, saying "Hello" in a neutral tone. This was 
done to ensure that the experimenter entering would not startle the dogs. The experimenter walked up to the dog and stood by its side, facing the wall and avoiding any eye contact. Meanwhile, the handler set up and refilled the puzzletoy. Then, as the handler walked to the opposite side of the room, the experimenter turned around to face the toy. The handler stood facing the wall with her back turned to the dog and the experimenter. She quickly left four pieces of food on a small shelf beside her and monitored the dog's behaviour on a mobile device that was connected to the experimenter's video camera. As soon as the handler saw the dog looking back at the experimenter (or after a maximum time of $2 \mathrm{~min}$ ), she walked back to the dog while the experimenter walked to the shelf to pick up the food and sat down in front of the puzzle-toy to begin the demonstration according to the conditions:

\subsubsection{Nice \& Skilful demonstration}

The experimenter spoke with a high pitched voice while effectively removing the blocks from the toy and revealing the pieces of food one by one; she established eye contact with the dog each time she spoke.

\subsubsection{Nice \& No-help demonstration}

The experimenter spoke with a high pitched voice, but did not attempt to use the toy; instead, she leaned over the toy and then helplessly shrugged her shoulders while establishing eye contact with the dog. These movements were repeated four times to counterbalance the activity level of the skilful demonstration.

\subsubsection{Ignoring \& Skilful demonstration}

The experimenter avoided eye contact and talked to herself in a neutral voice as if bored by the task, while effectively removing the blocks from the toy and revealing the pieces of food one by one.

\subsubsection{Ignoring \& No-help demonstration}

The experimenter avoided eye contact and talked to herself in a neutral voice as if bored by the task, and did not attempt to use the toy; she leaned over the toy and then helplessly shrugged her shoulders while looking at the toy. These movements were repeated four times, to counterbalance the activity level.

At the end of the demonstration, the experimenter walked away from the toy saying: "All done" in the Skilful demonstrations, and "I don't get it" in the No-help demonstrations. As in Study 1, it was necessary to ensure that dogs received the same amount of food during both demonstrations to avoid any food related bias. Therefore, at the end of No-help demonstrations, the experimenter inconspicuously dropped the food she had in her hand placing it as close as possible to the toy. Then, she turned around and sat on a chair, facing the toy but staring at her lap to avoid eye contact. The handler then walked the dog to the apparatus, letting it eat the food, before walking it to the Test Room. 


\subsubsection{Test (unsolvable task)}

Now that dogs had a chance to gather information about the experimenter and whether she was skilful in solving a problem or rather would not help them, as well as whether she was nice to them or rather ignored them, dogs were given a chance to request help from the experimenter in the unsolvable task. Upon entering the Test Room, the handler secured the lead to a wall hook. At the same time the experimenter entered and stood with her back against the wall, so that she was $1 \mathrm{~m}$ away from the apparatus. The handler showed the dog one piece of hot-dog and placed it on the wooden board in front of the metal basket; she then centred the dog in the room and let it retrieve the food; she repeated this twice more. On the second repetition, she took a larger chunk of hot-dog and dropped it inside the basket, making sure the dog was watching. After centring the dog, she quickly left the room and waited in the adjacent room for $2 \mathrm{~min}$. During this time, the experimenter stood still, as in Study 1. After the 2 min elapsed, the handler returned to the room and the test was over.

\subsubsection{Behaviour analysis}

Digital video footage was taken for all trials and the Solomon Coder software (beta 091110, copyright 2006-2008 by András Péter, developed at ELTE TTK Department of Ethology, Budapest, Hungary) was used to code dogs' behaviour during the unsolvable task. The coder (RMS) was unaware of the conditions at the time of coding.

Looks towards the experimenter and towards the food were recorded in the same way as in Study 1. However, this time all looks towards the experimenter were recorded, in order to measure whether being nice rather than ignoring the dog had an effect on their interest in the experimenter. The frequency of gaze alternations between the experimenter and the food was recorded with the aim to assess the effect of the conditions on the dogs' help requests.

A random selection of the video material (20\%) was coded by a second coder, naïve to the role of each experimenter. The correlation between the two coders was calculated using Spearman $r$, and inter-coder reliability was assessed according to the limits given by Landis and Koch (1977). Inter-observer reliability was excellent for the frequency of gazes to the experimenter $\left(r_{s}=0.82\right.$, $N=11, p=0.01)$ and their duration $\left(r_{s}=0.94, N=11, p<0.01\right)$; it was substantial for the latencies of looks $\left(r_{s}=0.77, N=11, p=0.01\right)$.

\subsubsection{Statistical analysis}

Data were analysed using IBM SPSS Statistics version 22. The KolmogorovSmirnov test for normality revealed that the data were not normally distributed, thus non-parametric tests (two-tailed) were used.

\subsection{Results}


Overall, the independent samples Kruskal-Wallis test indicated no significant difference between groups in the baseline latency to look at the experimenter, i.e. before the demonstration $\left(M d n_{\text {Niceskilful }}=5.99\right.$ interquartile range $1.60-$ $120.00, M d n_{\text {NiceNoHelp }}=7.68$ interquartile range $5.58-17.23$, $M d n_{\text {IgnoreSkilful }}=21.68$ interquartile range $11.13-33.25, M d n_{\text {IgnoreNoHelp }}=25.04$ interquartile range $\left.13.52-30.33, H_{(3)}=1.75, p=0.627, \varepsilon^{2}=0.06\right)$.

The independent samples Kruskal-Wallis test indicated no difference between the four conditions in the latency and duration of looking back behaviours towards the experimenter. Similarly, the frequency of gaze alternations between experimenter and food did not vary significantly across conditions (Table 3 ).

Table 3.

\section{Looks towards the experimenter and gaze alternations, results of independent samples Kruskal-Wallis test $(\mathrm{N}=48)$.}

\begin{tabular}{|c|c|c|c|c|c|c|c|c|c|c|c|}
\hline & $\begin{array}{l}\text { Nice } \\
\text { Skilful } \\
\end{array}$ & & $\begin{array}{l}\text { Nice } \\
\text { No help } \\
\end{array}$ & & $\begin{array}{l}\begin{array}{l}\text { Ignore } \\
\text { Skilful }\end{array} \\
\end{array}$ & & $\begin{array}{l}\text { Ignore } \\
\text { No help }\end{array}$ & & & & \\
\hline & $\overline{M d n}$ & $\mathrm{IQR}$ & $M d n$ & $\mathrm{IQR}$ & $M d n$ & $\mathrm{IQR}$ & $M d n$ & IQR & $H_{(3)}$ & $p$ & $\varepsilon^{2}$ \\
\hline Looking back latency (s) & 18.30 & $0.00-1.78$ & 21.90 & $0.00-4.15$ & 32.25 & $0.00-0.00$ & 30.45 & $0.00-1.25$ & 4.54 & 0.21 & 0.09 \\
\hline Looking back duration (s) & 10.70 & $3.55-23.80$ & 4.85 & $2.28-9.98$ & 8.85 & $5.88-19.30$ & 5.00 & $1.35-7.10$ & 3.73 & 0.29 & 0.08 \\
\hline Gaze alternations frequency & 3.00 & $1.00-6.25$ & 3.00 & $22.8-49.25$ & 5.00 & $1.00-7.25$ & 3.00 & $1.75-6.00$ & 0.71 & 0.87 & 0.01 \\
\hline
\end{tabular}

We were also interested in the effect that helpfulness alone (skilful help versus no-help) had on dogs' communication. Therefore, the data were merged into two groups based on the helpfulness of the demonstration: skilful demonstrations $(N=24)$, and no-help demonstrations $(N=24)$. A Mann-Whitney $U$ test indicated that there was a trend to significance as the looks back were longer in the skilful group compared to the no-help group $(p=0.05)$. None of the other measures (latency of looking back and frequency of gaze alternations) were affected (Table 4).

Table 4.

Effect of the type of help on looks back and gaze alternations, results of independent sample Mann-Whitney $U$ test $(N=48)$.

\begin{tabular}{|c|c|c|c|c|c|c|c|}
\hline & \multicolumn{2}{|c|}{ Skilful } & \multicolumn{2}{|c|}{ No-help } & \multirow[b]{2}{*}{$T$} & \multirow[b]{2}{*}{$p$} & \multirow[b]{2}{*}{$r$} \\
\hline & $M d n$ & $I Q R$ & $M d n$ & $I Q R$ & & & \\
\hline Looking back latency (s) & 0.00 & $0.00-0.95$ & 0.00 & $0.00-2.22$ & -.23 & 0.82 & -0.05 \\
\hline Looking back duration (s) & 9.20 & $\begin{array}{l}3.98- \\
20.65\end{array}$ & 4.90 & $1.35-8.58$ & 1.93 & 0.05 & -0.39 \\
\hline $\begin{array}{l}\text { Gaze alternations } \\
\text { frequency }\end{array}$ & 6.00 & $4.75-8.50$ & 6.00 & $3.00-8.00$ & 0.65 & 0.52 & 0.13 \\
\hline
\end{tabular}

Medians (Mdn) and interquartile ranges (IQR) have been reported; p-values have been corrected for multiple comparisons using Benjamini and Hochberg (1995) method. Effect sizes $(r)$ were calculated dividing the test statistics by the square root of the number of observations (Pallat, 2007).

Our last question was whether the dogs that experienced the nice demonstration would try to interact more with the experimenter. We regrouped the data based on the quality of the interaction during the demonstration into two groups: nice demonstrations $(N=24)$, and ignoring demonstrations $(N=24)$. A MannWhitney $U$ test found that none of the measures were affected (Table 5). 
Table 5.

Effect of the quality of interaction on looking back and gaze alternations, results of independent sample Mann-Whitney $U$ test $(N=48)$.

\begin{tabular}{|c|c|c|c|c|c|c|}
\hline \multirow[t]{2}{*}{ 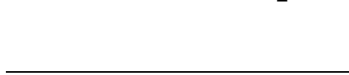 } & \multicolumn{6}{|c|}{$\begin{array}{ll}\text { Nice } & \text { Ignoring } \\
\end{array}$} \\
\hline & $M d n$ & $M d n$ & $I Q R$ & $T$ & $p$ & $r$ \\
\hline Looking back latency (s) & 0.00 & $0.00-2.670 .00$ & $0.00-0.00$ & -1.60 & 0.11 & -0.33 \\
\hline Looking back duration (s) & 5.90 & $2.65-16.506 .60$ & $2.55-15.75$ & 0.08 & 0.94 & 0.02 \\
\hline Gaze alternations frequency & 3.00 & $1.00-6.00 \quad 3.50$ & $1.00-7.25$ & 0.73 & 0.47 & 0.15 \\
\hline
\end{tabular}

Medians (Mdn) and interquartile ranges (IQR) have been reported; p-values have been corrected for multiple

comparisons using Benjamini and Hochberg (1995) method. Effect sizes $(r)$ were calculated dividing the test statistics by the square root of the number of observations (Pallat, 2007).

\subsection{Discussion}

In the current study, we were interested in whether the quality of the interaction with a human partner and human skilfulness, combined or alone, would affect dogs' looking back behaviour. We found that the dogs did not vary in their tendency to request help from the experimenter depending on whether she was nice and skilful, nice and unwilling to help, ignoring and skilful or ignoring and unwilling to help when faced with an unsolvable problem. However, the duration of looking back behaviour was longer, with a trend towards significance, for the dogs that received a skilful demonstration compared to dogs that received a demonstration that was not helpful. Although the results should be interpreted cautiously because they represent only a trend, which is not replicated in the other measures of the study, the possibility that dogs can take a human partner's helpfulness into account should not be excluded.

Finally, the frequency of gaze alternations was not affected by the helpfulness of the experimenter or the quality of the demonstration. Similar findings were obtained by Horn et al. (2012), who observed that dogs' proximity to the experimenter, rather than gazes, was affected by the human partner's behaviour. Smith and Litchfield (2013) also indicate that gaze alternations in the unsolvable task might be less frequent than overall looking behaviour towards the experimenter. It is possible that while the dogs' help requests did not vary across conditions in the current study, the dogs that experienced a skilful demonstration were overall more attentive to the experimenter and therefore looked at her more, which would explain why the duration of looks varied, while the frequency of gaze alternations did not.

\section{General discussion}

The results of Study 1 indicate that dogs did not form a preference between two experimenters based on a demonstration when requesting human help. It is possible that the dogs could not discriminate between the two experimenters or did not understand the demonstration. To exclude this possibility, in Study 2, the dogs observed only one experimenter and were allowed to use the puzzle-toy before the demonstration. Although the results showed that the dogs did not form a preference based on the helpfulness of the demonstration and the quality of the interaction, the dogs who received a skilful demonstration tended to look at the experimenter more than those who received a no-help demonstration (i.e. the experimenter did not attempt to help solving the problem). However, the dogs did not perform gaze alternations more often in any of the conditions. 
One possible explanation for these results could be that dogs might not be able to take into account their opinion about humans when requesting human help. This explanation would be in line with the hypothesis that only humans and evolutionarily close species, such as the chimpanzee, have the ability to understand when they require help, discriminate partners based on their skills, and then choose the best collaborator (Melis et al., 2006; Melis and Semmann, 2010). Such explanation is in agreement with recent evidence in the literature on dogs, suggesting that although they might be able to choose the appropriate collaborative partner, they likely did so by associating the specific location of the partner with food (Petró et al., 2016). Since we were interested in investigating dogs' ability to recognise and use specific characteristics of a partner, such as skilfulness, when help is required, we purposely controlled for other confounders: we performed the demonstration and the test phase in separate rooms and, when more than one partner was present, we counterbalanced their position across different trials. Therefore, our results should not be biased by factors such as food or location associations and may possibly indicate that dogs might not be able to discriminate humans based on their skills.

Unexpectedly, the dogs in Study 2 did not even take the quality of the interaction into account, i.e. nice versus ignoring, when requesting human help. Dogs appear to be able to recognise such characteristics in humans ( Nitzschner et al., 2012) and it could be expected that dogs would decide to interact more with a nice partner rather than one who had ignored them. According to the current findings, it seems that while dogs can form an opinion about humans based on whether they are nice to them, such opinion does not affect partner choices in dogs when they are facing a problem. There could be two possible explanations for this result. One possibility is that requesting help is not a flexible behaviour in dogs. As previous findings suggest, this may be affected by past experience ( Topál et al., 1997; Marshall-Pescini et al., 2009; D'Aniello et al., 2015 ; D'Aniello and Scandurra, 2016) but possibly not by short term contingencies. According to the domestication hypothesis ( Hare et al., 2002 ; Miklósi et al., 2004), dogs adapted to life with humans and formed a specialization for communication with humans, especially in cooperative contexts ( Bräuer et al., 2006 ; Reid, 2009). It is possible that, as a result, dogs evolved a strong predisposition to request human help regardless of the abilities of the human partner involved. Another possibility is that our results were affected by the measures we chose. It has been hypothesised that dogs have evolved the predisposition to look at humans when facing an unsolvable problem (Miklósi et al., 2003) and there are individual differences in dogs' tendency to look at humans ( Topál et al., 1997; Marshall-Pescini et al., 2009; D'Aniello et al., 2015 ; D'Aniello and Scandurra, 2016). Recent findings also show that dogs' breed and age affect their tendency to look at humans during an unsolvable task ( Konno et al., 2016; Gacsi et al., 2009). Although we had a good age distribution and a relatively wide representation of breeds, our sample did not allow for comparisons between breeds or age groups. These new findings should be taken into account for future research; however, the results of the current study do not allow us to draw definitive conclusions about whether dogs have the cognitive ability to form an opinion based on skilfulness. It is possible that the low prevalence of eye contact 
in certain breeds might have affected the results. Therefore, a future study could investigate only breeds, and age groups most keen to form eye contact, i.e. hounds, retrievers, and working dogs, and older dogs (Konno et al., 2016) and cooperative breeds (Gacsi et al., 2009). If the results of this future study showed that this type of communication is particularly evident in this subgroup, it would provide supporting evidence for the trend that we found in this study.

Additionally, previous findings indicate that the persistence of dogs' gaze may be particularly relevant in dog-human collaborative communication in general (Piotti and Kaminski, 2016) and in the unsolvable task specifically (MarshallPescini et al., 2017); therefore, further attention should be given to this measure as an additional measure other than frequency of gazes.

Our findings could not confirm whether dogs can take skilfulness into account when requesting human help. Previous research provides controversial evidence. Dogs can coordinate their actions to that of a human partner in order to solve a cooperative problem, although the level of skilfulness of the partner was not manipulated (Ostojić and Clayton, 20130stojić and Clayton 2013). In a problem solving situation, dogs were observed to flexibly adjust their behaviour to problem-specific actions of a human partner, although this did not affect dogs' tendency to request help, i.e. to look back at the human (Horn et al., 2012). However, a replication of the same study and the use of inanimate objects as partners suggested that more parsimonious explanations, such as the association of a specific location with food, may explain dogs' behaviour (Petró et al., 2016). Finally, dogs can form an opinion about humans based on the quality of an interaction they have with the human (Nitzschner et al., 2012). They also coordinate with other dogs in a cooperative task, but they do not appear to monitor each other's behaviour while cooperating (Bräuer et al., 2013). Our findings add information to this body of research but could not confirm this possibility, though they do not exclude it. Due to dogs' ability to cooperate with humans (Ostojić and Clayton, 20130stojić and Clayton 2013), such ability might be expected and should be further investigated.

The unsolvable task is a very simple test, based on a behaviour that dogs are evolutionarily predisposed to perform, i.e. looking back (Miklósi et al., 2003). However, previous evidence, together with our findings, highlights some limitations of the test. The looking back behaviour is largely affected by longterm direct experiences in the life of dogs, e.g. specific training, housing conditions (D'Aniello et al., 2015 ; Scandurra et al., 2015), and breed (Konno et al., 2016; Gacsi et al., 2009). Therefore, studies employing the unsolvable task in a group comparison design should adjust for this, for example by measuring a baseline level of looking behaviour or counterbalancing potential confounders. Dogs appear to find it difficult to grasp elaborate demonstrations ( Horn et al., 2012 ; Petró et al., 2016), especially if they do not have a chance to directly interact with the apparatus used for the demonstration. The results of Study 1 in the current work and Horn et al. (2012) suggest that it may be difficult for dogs to recognise subtle differences in the skills of two human partners. Therefore, it seems important for manipulations to be simple and very salient when investigating the understanding of skilfulness in dogs. 
Finally, Abdai and Miklósi (2016) recently suggested that different procedures might measure different aspects of reputation forming. Therefore, it may be possible that the skill, if present, might not be evident in certain contexts but only in others. Thus, another possibility is to investigate reputation forming through different paradigms. For example cooperative activities, e.g. based on hunting-like behaviours (Bräuer et al., 2013 ; Ostojić and Clayton, 2013), could be adopted to further investigate reputation forming in dogs and their ability to select the best cooperative partner.

\section{Funding}

This work was funded by the University of Portsmouth (U.K.).

\section{Conflict of interest}

Patrizia Piotti declares that she has no conflict of interest. Rebecca Marie Spooner declares that she has no conflict of interest. Hoi-Lam Jim declares that she has no conflict of interest. Juliane Kaminski declares that she has no conflict of interest.

\section{Ethical approval}

All applicable international, national, and institutional guidelines for the care and use of animals were followed. All the procedures were in line with the guidelines of the International Society for Applied Ethology.

\section{Acknowledgements}

We would like to thank the dog owners. Without their support this work would not be possible. We also thank Ariana Weldon, Georgie Smith and Derry Taylor for their help with data collection and reliability coding, and Marc Martin, Graham Malyon, and Jenny Mackellar for the technical support. We would like to thank Prof Daniel Mills for his comments on an earlier version of this manuscript

\section{Appendix A. Supplementary data}

The following are Supplementary data to this article:

SI 1: Dogs' information

SI 2: Raw data

\section{References}

\section{J. Abdai, A. Miklósi}

The origin of social evaluation, social eavesdropping, reputation formation, image scoring or what you will

Front. Psychol., 7 (2016), pp. 1-13 https://doi.org/10.3389/fpsyg.2016.01772

K. Asakawa-Haas, M. Schiestl, T. Bugnyar, J.J.M. Massen

Partner choice in raven (Corvus corax) cooperation

PLoS One, 11 (2016), pp. 1-15 https://doi.org/10.1371/journal.pone.0156962 
R. Axelrod, W.D. Hamilton

The evolution of cooperation

Science (80-), 211 (1981), pp. 1390-1396

https://doi.org/10.1126/science.7466396

M. Bentosela, A. Jakovcevic, A.M. Elgier, A.E. Mustaca, M.R. Papini

Incentive contrast in domestic dogs (Canis familiaris)

J. Comp. Psychol., 123 (2) (2009), p. 125 https://doi.org/10.1037/a0013340

J. Bräuer, J. Kaminski, J. Riedel, et al.

Making inferences about the location of hidden food: social dog, causal ape

J. Comp. Psychol., 120 (2006), pp. 38-47 https://doi.org/10.1037/0735-

7036.120.1.38

J. Bräuer, M. Bös, J. Call, M. Tomasello

Domestic dogs (Canis familiaris) coordinate their actions in a problem-solving task

Anim. Cogn., 16 (2013), pp. 273-285 https://doi.org/10.1007/s10071-012-

0571-1

H. Chijiiwa, H. Kuroshima, Y. Hori, et al.

Dogs avoid people who behave negatively to their owner: third-party affective evaluation

Anim. Behav., 106 (2015), pp. 123-127

https://doi.org/10.1016/j.anbehav.2015.05.018

J.J. Cooper, C. Ashton, S. Bishop, et al.

Clever hounds: social cognition in the domestic dog (Canis familiaris)

Appl. Anim. Behav. Sci., 81 (2003), pp. 229-244 https://doi.org/10.1016/S01681591(02)00284-8

B.D. D'Aniello, A. Scandurra

Ontogenetic effects on gazing behaviour: a case study of kennel dogs (Labrador

Retrievers) in the impossible task paradigm

Anim. Cogn., 19 (2016), pp. 565-570 https://doi.org/10.1007/s10071-016-

0958-5

B.D. D'Aniello, A. Scandurra, E. Prato-Previde, P. Valsecchi

Gazing toward humans: a study on water rescue dogs using the impossible task paradigm

Behav. Processes, 110 (2015), pp. 68-73

https://doi.org/10.1016/j.beproc.2014.09.022

N. Emler

A social psychology of reputation

Eur. Rev. Soc. Psychol., 1 (1990), pp. 171-193

https://doi.org/10.1080/14792779108401861 
E. Fehr, U. Fischbacher

Social norms and human cooperation

Trends Cogn. Sci., 8 (2004), pp. 185-190

https://doi.org/10.1016/j.tics.2004.02.007

E. Freidin, N. Putrino, M. D’Orazio, M. Bentosela

Dogs' eavesdropping from people's reactions in third party interactions

PLoS One, 8 (2013), pp. 1-8 https://doi.org/10.1371/journal.pone.0079198

M. Gácsi, P. McGreevy, E. Kara, Á. Miklósi.

Effects of selection for cooperation and attention in dogs.

Beh. Br. Fun., 5 (2009), p31. https://doi.org/10.1186/1744-9081-5-31

F. Gaunet, B.L. Deputte

Functionally referential and intentional communication in the domestic dog: effects of spatial and social contexts

Anim. Cogn., 14 (2011), pp. 849-860 https://doi.org/10.1007/s10071-011-

0418-1

B. Hare, M. Brown, C. Williamson, M. Tomasello

The domestication of social cognition in dogs

Science, 298 (2002), pp. 1634-1636 https://doi.org/10.1126/science.1072702

M.T.E. Heberlein, D.C. Turner, F. Range, Z. Virányi

A comparison between wolves, Canis lupus, and dogs, Canis familiaris, in showing behaviour towards humans

Anim. Behav., 122 (2016), pp. 59-66

https://doi.org/10.1016/j.anbehav.2016.09.023

E. Herrmann, S. Keupp, B. Hare, et al.

Direct and indirect reputation formation in nonhuman great apes (Pan paniscus, Pan troglodytes, Gorilla gorilla, Pongo pygmaeus) and human children (Homo sapiens)

J. Comp. Psychol., 127 (2013), pp. 63-75 https://doi.org/10.1037/a0028929

L. Horn, Z. Virányi, A. Miklósi, et al.

Domestic dogs (Canis familiaris) flexibly adjust their human-directed behavior to the actions of their human partners in a problem situation

Anim. Cogn., 15 (2012), pp. 57-71 https://doi.org/10.1007/s10071-011-0432-3

S.H. Hurlbert

Pseudoreplication and the design of ecological field experiments

Ecol. Monogr., 54 (2) (1984), pp. 187-212 https://doi.org/10.2307/1942661

A. Konno, T. Romero, M. Inoue-Murayama, et al.

Dog breed differences in visual communication with humans

PLoS One, 11 (2016), p. e0164760

https://doi.org/10.1371/journal.pone.0164760 
J.R. Landis, G.G. Koch

The measurement of observer agreement for categorical data

Biometrics, 33 (1977), pp. 159-174 https://doi.org/10.2307/2529310

S. Marshall-Pescini, C. Passalacqua, S. Barnard, et al.

Agility and search and rescue training differently affects pet dogs' behaviour in socio-cognitive tasks

Behav. Processes, 81 (2009), pp. 416-422

https://doi.org/10.1016/j.beproc.2009.03.015

S. Marshall-Pescini, C. Passalacqua, A. Ferrario, et al.

Social eavesdropping in the domestic dog

Anim. Behav., 81 (2011), pp. 1177-1183

https://doi.org/10.1016/j.anbehav.2011.02.029

A.P. Melis, D. Semmann

How is human cooperation different?

Philos. Trans. R. Soc. B Biol. Sci., 365 (2010), pp. 2663-2674

https://doi.org/10.1098/rstb.2010.0157

A.P. Melis, B. Hare, M. Tomasello

Chimpanzees recruit the best collaborators

Science (80-), 311 (2006), pp. 1297-1300

https://doi.org/10.1126/science.1123007

A. Miklósi, E. Kubinyi, J. Topál, M. Gácsi

A simple reason for a big difference: wolves do not look back at humans but dogs do

Curr. Biol., 13 (9) (2003), pp. 763-766

A. Miklósi, J. Topál, V. Csányi

Comparative social cognition: what can dogs teach us?

Anim. Behav., 67 (2004), pp. 995-1004

https://doi.org/10.1016/j.anbehav.2003.10.008

M. Nitzschner, A.P. Melis, J. Kaminski, M. Tomasello

Dogs (Canis familiaris) evaluate humans on the basis of direct experiences only

PLoS One, 7 (10) (2012), p. e46880

https://doi.org/10.1371/journal.pone.0046880

M. Nitzschner, J. Kaminski, A.P. Melis, M. Tomasello

Side matters: potential mechanisms underlying dogs' performance in a social eavesdropping paradigm

Anim. Behav., 90 (2014), pp. 263-271

https://doi.org/10.1016/j.anbehav.2014.01.035

L. Ostojić, N.S. Clayton

Behavioural coordination of dogs in a cooperative problem-solving task with a conspecific and a human partner 
Anim. Cogn., 17 (2013), pp. 445-459 https://doi.org/10.1007/s10071-013-

0676-1

J. Pallant

SPSS Survival Manual

(3rd edition)McGraw Hill Open University Press, New York, NY (2007)

E. Petró, J. Abdai, A. Gergely, et al.

Dogs (Canis familiaris) adjust their social behaviour to the differential role of inanimate interactive agents

Anim. Cogn., 19 (2016), pp. 367-374 https://doi.org/10.1007/s10071-015-

0939-0

P. Piotti, J. Kaminski

Do dogs provide information helpfully?

PLoS One. 11 (2016) e0159797 https://doi.org/10.1371/journal.pone.0159797

P.J. Reid

Adapting to the human world: dogs' responsiveness to our social cues

Behav. Processes, 80 (2009), pp. 325-333

https://doi.org/10.1016/j.beproc.2008.11.002

S. Riemer, S.L. Ellis, S. Ryan, H. Thompson, O.H. Burman

A reappraisal of successive negative contrast in two populations of domestic dogs

Anim. Cogn., 19 (3) (2016), pp. 471-481 https://doi.org/10.1007/s10071-0150947-0

A. Scandurra, E. Prato-Previde, P. Valsecchi, et al.

Guide dogs as a model for investigating the effect of life experience and training on gazing behaviour

Anim. Cogn., 18 (2015), pp. 937-944 https://doi.org/10.1007/s10071-015-

0864-2

B.P. Smith, C.A. Litchfield

Looking back at looking back: operationalising referential gaze for dingoes in an unsolvable task

Anim. Cogn., 16 (2013), pp. 961-971 https://doi.org/10.1007/s10071-013-

0629-8

D. Sperber, N. Baumard

Moral reputation: an evolutionary and cognitive perspective

Mind Lang., 27 (2012), pp. 495-518 https://doi.org/10.1111/mila.12000

F. Subiaul, J. Vonk, S. Okamoto-Barth, J. Barth

Do chimpanzees learn reputation by observation? Evidence from direct and indirect experience with generous and selfish strangers

Anim. Cogn., 11 (2008), pp. 611-623 https://doi.org/10.1007/s10071-008-

0151-6 
M. Tomasello, M. Carpenter, J. Call, et al.

Understanding and sharing intentions: the origins of cultural cognition

Behav. Brain Sci., 28 (2005) https://doi.org/10.1017/S0140525x05000129 67591-735

J. Topál, A. Miklósi, V. Csányi

Dog-human relationship affects problem solving behavior in the dog

Anthrozoos, 10 (1997), pp. 214-224

https://doi.org/10.2752/089279397787000987

R.L. Trivers

The evolution of reciprocal altruism

Q. Rev. Biol., 46 (1971), pp. 35-57

M.A.R. Udell, C.D.L. Wynne

Ontogeny and phylogeny: both are essential to human-sensitive behaviour in the genus Canis

Anim. Behav., 79 (2010), pp. e9-e14

M.A.R. Udell, N.R. Dorey, C.D.L. Wynne

What did domestication do to dogs? A new account of dogs' sensitivity to human actions

Biol. Rev., 85 (2010), pp. 327-345

A.L. Vail, A. Manica, R. Bshary

Fish choose appropriately when and with whom to collaborate

Curr. Biol., 24 (2014), pp. R791-R793

https://doi.org/10.1016/j.cub.2014.07.033

F. Warneken, F. Chen, M. Tomasello

Cooperative activies in young children and chimpanzees

Child Dev., 77 (2006), pp. 640-663

C. Wedekind, M. Milinski

Cooperation through image scoring in humans

Science (80-), 288 (2000), pp. 850-852

https://doi.org/10.1126/science.288.5467.850

J. Wu, D. Balliet, P.A.M. Lange, Van

Reputation, gossip, and human cooperation

Soc. Pers. Psychol. Compass, 6 (2016), pp. 350-364

C.D.L. Wynne, M.A.R. Udell, K.A. Lord

Ontogeny's impact on human-dog communication

Anim. Behav., 76 (4) (2008), pp. e1-e4 


\section{Online resource: dogs' information}

Study 1

Table 1 Characteristics of the dogs and identity of the helper assigned to each dog in Study 1

\begin{tabular}{|c|c|c|c|c|c|c|}
\hline Name & Gender & Age (years) & Breed & Skilful & $\begin{array}{l}\text { First } \\
\text { Demo } \\
\text { (1) }\end{array}$ & $\begin{array}{l}\text { Skilful } \\
\text { Side }^{(2)}\end{array}$ \\
\hline$\overline{\text { Alfie }}$ & $\mathrm{M}$ & 2.4 & Cross & RMS & $\mathrm{S}$ & RLRL \\
\hline Barnsley & M & 3.8 & Cross & PP & $\mathrm{S}$ & LRLR \\
\hline Bertie & M & 2.2 & Jack Russell Terrier & PP & $\mathrm{U}$ & LRLR \\
\hline Biscuit & M & 2.2 & Border Collie & PP & S & LRRL \\
\hline Bonnie & $\mathrm{F}$ & 3.1 & Cross & RMS & S & RLLR \\
\hline Bracken & $\mathrm{F}$ & 7.4 & Labrador & PP & $\mathrm{U}$ & RLRL \\
\hline Buddie & M & 4.7 & Cross & RMS & $\mathrm{U}$ & LRLR \\
\hline Chester B & M & 2.6 & Bassett Sound & RMS & $\mathrm{U}$ & LRLR \\
\hline Chester S & M & 1.9 & Spaniel & PP & S & LRLR \\
\hline Dali & M & 2.4 & Labrador & RMS & S & RLRL \\
\hline Dolly & $\mathrm{F}$ & 6.2 & Cross & PP & $\mathrm{U}$ & LRRL \\
\hline Fudge & M & 4.8 & Cross & RMS & $\mathrm{U}$ & LRRL \\
\hline Gus & M & 8.1 & Labrador & PP & $\mathrm{U}$ & RLLR \\
\hline Harvey & M & 1.1 & Schnauzer & RMS & S & LRLR \\
\hline Horace & M & 4.2 & Italian spinone & PP & $\mathrm{U}$ & RLLR \\
\hline Lexi & M & 2.2 & Rottweiler & PP & S & RLLR \\
\hline Lucy & $\mathrm{F}$ & 8.0 & Cross & RMS & $\mathrm{U}$ & RLLR \\
\hline Marcel & M & 3.8 & French Bulldog & PP & S & RLLR \\
\hline MaxL & M & 6.3 & Labrador & RMS & S & LRLR \\
\hline MaxP & M & 4.2 & Cross & PP & $\mathrm{U}$ & LRLR \\
\hline Monty & M & 3.5 & Cross & RMS & S & LRRL \\
\hline Nugget & M & 8.0 & Labrador & PP & S & RLRL \\
\hline Oscar & M & 2.4 & Bichon & PP & $\mathrm{U}$ & LRRL \\
\hline Padme & $\mathrm{F}$ & 10.2 & Border Terrier & RMS & S & LRRL \\
\hline Poppy & $\mathrm{F}$ & 1.3 & Labrador & PP & S & RLRL \\
\hline Ralph & M & 5.8 & Cross & RMS & $\mathrm{U}$ & RLLR \\
\hline Roxy & $\mathrm{F}$ & 1.3 & Cross & RMS & S & RLLR \\
\hline Sammy & $\mathrm{F}$ & 9.5 & Border Collie & RMS & $\mathrm{U}$ & RLRL \\
\hline Smudge & M & 4.0 & Spaniel & RMS & $\mathrm{U}$ & RLRL \\
\hline Tigger & M & 8.2 & Cross & PP & S & LRRL \\
\hline Wilf & M & 7.5 & Cross & PP & $\mathrm{U}$ & RLRL \\
\hline Wilson & M & 1.8 & Cross & RMS & $\mathrm{U}$ & LRRL \\
\hline $\begin{array}{ll}\text { (1) } & \mathrm{T} \\
\text { (2) } & \mathrm{Pc} \\
& \text { th } \\
& \mathrm{W}\end{array}$ & $\begin{array}{l}\text { Cype of demons } \\
\text { osition of the } s \\
\text { he apparatus. F } \\
\text { which were not } \\
\text { kilful experime } \\
\text { ight. }\end{array}$ & $\begin{array}{l}\text { n, skilful (S) } \\
\text { experiment } \\
\text { ch dog it wa } \\
\text { ted more the } \\
\text { vas on left o }\end{array}$ & $\begin{array}{l}\text { or unskilful (U), tha } \\
\mathrm{r} \text { during the unsolvo } \\
\text { counterbalanced th } \\
\mathrm{n} \text { twice in a row. M } \\
\text { the first trial, and } \mathrm{f}\end{array}$ & $\begin{array}{l}\text { he dogs } \\
\text { e task, } \\
\text { umber o } \\
\text { over, for }\end{array}$ & $\begin{array}{l}\text { ere pres } \\
\text { to left } \\
\text { left and } \\
\text { lalf of th }\end{array}$ & $\begin{array}{l}\text { nted first } \\
\text { or side of } \\
\text { ight, } \\
\text { dogs the } \\
\text { vas on }\end{array}$ \\
\hline
\end{tabular}


Study 2

Table 2 Characteristics of the dogs and condition assigned to each dog in Study 2

\begin{tabular}{|c|c|c|c|c|}
\hline Name & Gender & $\begin{array}{l}\begin{array}{l}\text { Age } \\
\text { (years) }\end{array}\end{array}$ & Breed & Condition \\
\hline Badger & $\mathrm{M}$ & 2 & Newfoundland & Nice \& Skilful \\
\hline Bailey G & M & 7 & Cross & Nice \& Skilful \\
\hline Bailey P & $\mathrm{F}$ & 3 & Cross & Nice \& Skilful \\
\hline Budi & M & 1 & German Shepherd & Nice \& Skilful \\
\hline Buzz & M & 6 & Cross & Nice \& Skilful \\
\hline Dizzy & $\mathrm{F}$ & 4.5 & Golden retriever & Nice \& Skilful \\
\hline Fudge & M & 1 & Cavalier King Charles sp & Nice \& Skilful \\
\hline Kiba & M & 3 & Dalmatian & Nice \& Skilful \\
\hline Macey & $\mathrm{F}$ & 8 & Labrador & Nice \& Skilful \\
\hline Monty & M & 1.5 & Labrador & Nice \& Skilful \\
\hline Phoebe & $\mathrm{F}$ & 1.5 & Cross & Nice \& Skilful \\
\hline Vialli & M & 2 & Whippet & Nice \& Skilful \\
\hline Arya & $\mathrm{F}$ & 1.5 & German Shepherd & Nice \& No-help \\
\hline Charlie & M & 10 & Cross & Nice \& No-help \\
\hline Freddy & M & 5.5 & Cross & Nice \& No-help \\
\hline Harry & M & 4.5 & Cross & Nice \& No-help \\
\hline Lenny & M & 2 & Cross & Nice \& No-help \\
\hline Molly & $\mathrm{F}$ & 7.5 & Bull Terrier & Nice \& No-help \\
\hline Nessie & $\mathrm{F}$ & 1.5 & Labrador & Nice \& No-help \\
\hline Poppy & $\mathrm{F}$ & 11 & Cross & Nice \& No-help \\
\hline Summer & $\mathrm{F}$ & 8 & Labrador & Nice \& No-help \\
\hline Tod & M & 5 & Spaniel & Nice \& No-help \\
\hline Tommy & $\mathrm{M}$ & 2 & Spaniel & Nice \& No-help \\
\hline Woody S & M & 4.5 & French Bulldog & Nice \& No-help \\
\hline Bailey B & M & 3 & Labrador & Ignore \& Skilful \\
\hline Dotty & $\mathrm{F}$ & 3 & Cross & Ignore \& Skilful \\
\hline Eddie & M & 1 & Cross & Ignore \& Skilful \\
\hline Lilly & $\mathrm{F}$ & 2 & Cross & Ignore \& Skilful \\
\hline Lucca & M & 3 & Labrador & Ignore \& Skilful \\
\hline Mavis & $\mathrm{F}$ & 2 & Border Terrier & Ignore \& Skilful \\
\hline Meeka & $\mathrm{F}$ & 3 & Cross & Ignore \& Skilful \\
\hline Ninja & $\mathrm{F}$ & 2 & Labrador & Ignore \& Skilful \\
\hline Ozzy & M & 2 & Pug & Ignore \& Skilful \\
\hline Sasha & $\mathrm{F}$ & 2 & Border Collie & Ignore \& Skilful \\
\hline Toby & $\mathrm{M}$ & 6 & Spaniel & Ignore \& Skilful \\
\hline Willow & $\mathrm{F}$ & 8 & Cross & Ignore \& Skilful \\
\hline Belle & $\mathrm{F}$ & 3 & English Bulldog & Ignore \& No-help \\
\hline Clover & M & 1.5 & Tibetan Terrier & Ignore \& No-help \\
\hline Copper & $\mathrm{M}$ & 3 & Border Collie & Ignore \& No-help \\
\hline Diesel & M & 5 & Cross & Ignore \& No-help \\
\hline Harvey & M & 5 & Labrador & Ignore \& No-help \\
\hline Honey & $\mathrm{F}$ & 9 & Labrador & Ignore \& No-help \\
\hline
\end{tabular}




\begin{tabular}{lllll} 
Luna & F & 6 & Border Collie & Ignore \& No-help \\
Milo & M & 7 & Cross & Ignore \& No-help \\
Saphie & F & 8 & Labrador & Ignore \& No-help \\
Spud & M & 2 & Jack Russell Terrier & Ignore \& No-help \\
Woody C & M & 8 & Cross & Ignore \& No-help \\
Zayla & F & 2 & German Shepherd & Ignore \& No-help \\
\hline
\end{tabular}

Additional Descriptive Statistics for Study 2

In the Nice-Skilful group 4 females and 8 males $\left(\mathrm{M}_{\text {age }}=3.37\right.$ years, $\mathrm{SD}_{\text {age }}=2.43, \mathrm{Min}_{\text {age }}=$ 1.00 year, $\mathrm{Max}_{\mathrm{age}}=8.00$ years) and 8 dogs were pure breeds $(67 \%)$, in the Nice-No-help group were 5 females and 7 males $\left(\mathrm{M}_{\text {age }}=5.25\right.$ years, $\mathrm{SD}_{\text {age }}=3.28, \mathrm{Min}_{\text {age }}=1.50$ year, $\operatorname{Max}_{\text {age }}=11.00$ years) and 7 dogs were pure breeds (58\%), in the Ignoring-Skilful group were 7 females and 5 males and 7 dogs were pure breeds (58\%), and in the Ignoring-No-help group were 5 females $\left(\mathrm{M}_{\text {age }}=3.08\right.$ years, $\mathrm{SD}_{\text {age }}=1.97, \mathrm{Min}_{\text {age }}=1.00$ year, $\mathrm{Max}_{\text {age }}=8.00$ years $)$ and 7 males $\left(\mathrm{M}_{\mathrm{age}}=4.95\right.$ years, $\mathrm{SD}_{\mathrm{age}}=2.65, \mathrm{Min}_{\mathrm{age}}=1.50$ year, $\mathrm{Max}_{\mathrm{age}}=9.00$ years $)$ and $9 \mathrm{dogs}$ were pure breeds $(75 \%)$. 